\title{
CLONING OF ROTAVIRUS OUTER CAPSID PROTEIN (VP7) GENE INTO THE pGEM VECTOR
}

\author{
Mazaher Khodabandehloo, Mahmoud Shamsi Shahrabadi ${ }^{1 *}$, Hossein Keyvani ${ }^{1}$, and Bijan Bambai ${ }^{2}$ \\ ${ }^{1}$ Virology department of Iran University of medical sciences, ${ }^{2}$ national research center of genetic engineering and \\ biotechnology
}

\begin{abstract}
In humans the group A rotaviruses are associated with endemic diarrhea in children under the age of 5 , leading to approximately 800,000 deaths every year. Introduction of rotavirus vaccines into childhood immunization programs can contribute to substantial reduction in mortality from rotavirus gastroenteritis in developing countries and virtually eliminating hospitalizations due to rotavirus gastroenteritis, a heavy burden in developed countries. A reassortant Rhesus-human rotavirus vaccine, Rotashield was manufactured and marketed in 1998. Nine months later a small number of cases of intussusceptions were identified, leading to the withdrawal of vaccine. Important questions remain for these oral live vaccines related with safety and side effects as well as production costs, thus development of second generation of nonreplicating rotavirus vaccine should be considered as an alternative to live vaccines. VP7 is major outer capsid glycoprotein; can induce production of neutralizing antibodies. Regarding these concepts we cloned VP7 gene of SA11 rotavirus in pGEM vector for future expression. With large scale expression and purification of VP7 protein, it will be convenient to study VP7 antigenic, immunogenic, biologic functions and its potential for vaccine development.BSC-1 cells were grown as a monolayer. Simian rotavirus, SA11 was cultured. Oligonucleotide forward and reverse primers, specific for gene segment 9 which encodes VP7, were synthesized, according to dsRNA gene segment 9 of simian rotavirus SA11 sequence data at NCBI GeneBank. Rotavirus ds-RNA was extracted and used as template for reverse transcription to synthesize cDNA from both viral strands. cDNA product of RT-PCR was cloned into $\mathrm{pGEM}^{\circledR}-5 \mathrm{Zf}(-)$ vector and the results showed that rotavirus genome segment 9 was cloned into pGEM $^{\circledR}-5 \mathrm{Zf}(-)$ vector and confirmed by restriction enzyme and sequencing. Sequencing result was analyzed by BLAST software showing $100 \%$ homology with $9^{\text {th }}$ SA11 rotavirus genome segment in NCBI GeneBank.
\end{abstract}

Keywords: • Rotavirus $\bullet$ VP7 • cloning

\section{Introduction}

$\mathrm{R}$ otaviruses are members of family Reoviridae. The mature rotavirion is an icosahedron consisting of three concentric shells of protein that surround a genome of eleven segments of double-stranded RNA (dsRNA). This genome codes for six structural proteins (VP1-VP4, VP6 and VP7) and six nonstructural proteins (NSP1-NSP6) $(6,8,10)$. VP4 is an unglycosylated protein and forms

* Corresponding Author: Dr. Mahmoud Shamsi Shahrabadi: Virology department, Iran University of medical sciences, Rassul Akram Hospital, Neyayesh Ave., Sattarkhan St., Tehran, Iran.

P. Box: 1445613131 TelFax: 021-66509183

E-mail: Shahrabadi@hotmail.com dimeric spikes which in combination with VP7 constitute outer layer of viral capsid protein.

Moreover, VP4 has been shown to be a determinant of several important functions, such as cell attachment, entry to cells, hemagglutination, and neutralization $(3,6,9,10)$. Epitopic-specific antibodies to VP4 and VP7 correlate with protecting from infection; however, there is conflicting arguments about the role these antibodies in protection $(1,3,6,8,10)$.

Rotaviruses are causative agents of diarrheal diseases in a wide variety of mammalian animals. In humans the group A rotaviruses are associated with endemic diarrhea in children under the age of 5 year $(8,13,14)$. Because of the significant burden of rotavirus disease among children and 
animals worldwide, considerable efforts have been devoted towards the development of vaccines for disease prevention and control $(8,9,12)$. Nevertheless, host susceptibility and immunity to severe rotavirus-induced diarrhea are not fully understood. The role of homotypic and heterotypic immune responses in protection against disease is still controversial despite its relevance to vaccine development $(3,7,8)$. Introduction of rotavirus vaccines into childhood immunization programs can contribute to substantial reduction in mortality from rotavirus gastroenteritis $(12,14)$.

A reassortant rhesus-human rotavirus vaccine, Rotashield was manufactured and licensed by Wyeth Lederle and went into national use in the United States in 1998. Nine months later a small number of cases of intussusceptions were identified, leading to the withdrawal of vaccine (12). Other manufacturers have gone on to develop alternative live oral vaccines $(6,10,14)$.

Development of second generation of nonreplicating rotavirus vaccine is being considered as an alternative to live vaccines. Virus like particles constitutes a potential alternative approach $(5,14)$. Regarding these concepts we cloned VP7 gene of SA11 rotavirus into pGEM vector for future expression in suitable host (15). The protein obtained in large scale can be tested for vaccine developments.

\section{Material and Methods}

\section{Cell and virus culture}

African green monkey kidney fibroblastic cell line, BSC-1, was grown as monolayer in Dulbecco modified Eagle medium supplemented with $10 \%$ fetal calf serum, $2 \mathrm{mM}$ L-glutamine, $100 \mathrm{U}$ of penicillin and $100 \mu \mathrm{g}$ of streptomycin per $\mathrm{ml}$. Simian rotavirus SA11 was treated with $10 \mu \mathrm{g} / \mathrm{ml}$ trypsin for $60 \mathrm{~min}$ at room temperature to activate virus infectivity, then, propagated in BSC-1 cells using serum free medium supplemented with 0.5 $\mu \mathrm{g} / \mathrm{ml}$ trypsin. When infected cells showed $80 \%$ rotavirus cytopathic effect, cultured flasks were harvested by freeze-thawing three times and clarified by low speed centrifugation. The virus was concentrated by ultra-centrifugation on $40 \%$ sucrose cushion, at $20000 \mathrm{rpm}$ for $2 \mathrm{~h}$.

\section{Electrone microscope}

A grid prepared from concentrated virus was stained with $2 \%$ phosphotungestic acid, then, examined in electron microscope.

\section{RNA extraction}

RNA was extracted from viral pellet by RNAfast RNA extraction reagent, manufactured in National Research Center for Genetic Engineering and Biotechnology (NRCGEB), according to manual. Extracted RNA was electrophoresed on 10\% polyacrilamide(PAGE).RNA bands were identified by staining with ethidum bromide.

\section{Primer designing}

Oligonucleotide primers specific for genome segment no 9, which encodes VP7, were designed and synthesized from simian rotavirus SA11 sequence data at NCBI GeneBank (accession number K02028) (2), forward (from nucleotide no 47 to 72 ) and reverse (from nucleotide no 1006 to 1029). The nucleotide sequences of the primers were as follow:

VP7 Forward primer (VP7-F2):

5' -TAATGTATGGTATTGAATATACCACA- 3', and $\mathrm{VP} 7$ reverse primer (VP7-R2):

5' -GCAGCATTTTATTACAGAGTGTAG- 3'

\section{cDNA synthesis}

Rotavirus ds-RNA was used as template to synthesize cDNA copies from both viral strands. Reverse transcription reaction was carried out using a mixture of $10 \mu \mathrm{l}$ dsRNA template, $1 \mu \mathrm{l}$ of $100 \mu \mathrm{M}$ of each of the primers. The reaction tubes were heated at $95^{\circ} \mathrm{C}$ for $5 \mathrm{~min}$ and quickly cooled at $4{ }^{\circ} \mathrm{C}$, then the reverse transcription mixture consisting of $5 \mathrm{X}$ incubation buffer, $1 \mu 1$ of $2.5 \mathrm{mM}$ dNTPs mix,20U/ $\mu 1$ of RNase inhibitor (Fermentas) and $40 \mathrm{U}$ of M-MuLVirus reverse transcriptase (Roche) were added to total volume of $20 \mu 1$ and the tubes were incubated in a thermocycler at $37^{\circ} \mathrm{C}$ for 60 minutes.

\section{PCR amplification}

PCR reaction was carried out in total volume of 50 $\mu 1$ containing: $5 \mu 1$ of cDNA synthesis reaction, 5 $\mu 1$ of $10 \mathrm{X}$ PCR buffer, $1 \mu 1$ of $20 \mu \mathrm{M}$ of primers, 4 $\mu 1$ of $10 \mathrm{mM}$ dNTPs mix, and $2.5 \mathrm{U}$ of pfu DNA polymerase (Fermentas). Incubation program was an initial denaturation at $95^{\circ} \mathrm{C}$ for $5 \mathrm{~min}$, followed by $95^{\circ} \mathrm{C}$ for $30 \mathrm{sec}, 60^{\circ} \mathrm{C}$ for $30 \mathrm{sec}$ and $72{ }^{\circ} \mathrm{C}$ for 2 min for total of 35 cycles with final extension time at $72{ }^{\circ} \mathrm{C}$ for $10 \mathrm{~min}$. Final product was electrophoresed in $1 \%$ agarose gel.

\section{Verification of RT-PCR product}

The amplicon obtained was verified by agarose gel electrophoresis and purified by PCR product 
purification kit (Roche). PCR product of genome segment 9 was verified primarily by molecular weight and restriction enzyme DdeI digestion of amplicon (Roche).

\section{Ligation}

PCR product was introduced into the EcoR $\mathrm{V}$ cut pGEM $^{\circledR}-5 \mathrm{Zf}(-)$ vector (Promega) by direct blunt end ligation overnight at room temperature according to manual of T4 DNA ligase (Roche). Resulting plasmid, named VP7s-pGEM, was used to transform competent DH5- $\alpha$, E.coli cells.

\section{Preparation of competent cells \& Transformation}

Transformation of competent DH5- $\alpha$ cells was performed according to the method of Mandel \& Higa (11). Briefly, two $\mu 1$ of plasmid or ligation reaction was added to $100 \mu \mathrm{l}$ fresh competent cells and incubated in ice for $30 \mathrm{~min}$. The cells were incubated at $42^{\circ} \mathrm{C}$ for $1 \mathrm{~min}$ and immediately kept in ice for $30 \mathrm{~min}$. The cells were suspended in 900 $\mu 1$ of LB broth and agitated for $1 \mathrm{~h}$ at $37^{\circ} \mathrm{C}$. Then $50 \mu \mathrm{l}$ of the suspension was spread on agar plate containing ampicillin.

\section{Colony screening}

The clones were selected in LB agar plates, supplemented with $50 \mu \mathrm{g} / \mathrm{ml}$ ampicillin, $40 \mu \mathrm{l}$ of $2 \% \mathrm{x}$-gal and $7 \mu \mathrm{l}$ of $20 \%$ IPTG. Final screening was carried out by digestion of Miniprep plasmids (Plasmid extraction kit, Roche) with EcoRV (Roche) and NcoI (Fermentas) restriction enzymes. Confirmed clones were sequenced in the automated ABI 3130XL genetic analyzer to confirm the construction sequence by universal $\mathrm{T} 7$ and SP6 primers (BigDye Terminator V3.1 cycle Sequencing Kit). Sequencing result was analyzed by BLAST software.

\section{Result}

\section{Analysis of rotavirus RNA segments}

Rotavirus was concentrated and partially purified by ultra-centrifugation on $40 \%$ sucrose cushion at $20,000 \mathrm{rpm}$ for $1 \mathrm{~h}$. Fig 1 shows partially purified rotavirus which was used for RNA extraction. The virus was disrupted by either direct treatment with lysis mix (loading buffer) and briefly heating at $100^{\circ} \mathrm{C}$ or in some cases RNA was extracted by phenol chloroform extraction method. In both cases RNA was electrophoresed on $10 \%$ PAGE and it is shown in Fig 2, 11 bands of dsRNA was observing typical of rotavirus RNA pattern.

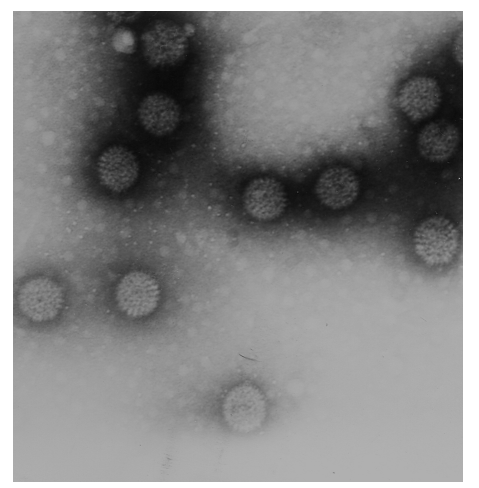

Figure 1 Partially purified rotavirus prepared by negative staining technique, $x 90000$
Figure 2 Electrophoresis pattern of rotavirus SA11 dsRNAs in 10\% PAGE, dsRNA segments were shown by numbers.

\section{RT-PCR}

The product of RT-PCR is shown in Fig. 4. A DNA band of 983 bp was observed after electrophoresis on $1 \%$ agarose gel. The identity of this band was confirmed by Dde I enzyme digestion which cleaves at nucleotides 144 and 262. Three segments of 118, 144 and $721 \mathrm{bp}$ of DNA after enzyme digestion were obtained (Fig. 4, lane 3). Because of low amount of DNA product, low concentration of agarose, these bands appeared very faint.

\section{VP7s cloning}

cDNA product of rotavirus genome segment 9 was cloned into $\mathrm{pGEM}^{\circledR}-5 \mathrm{Zf}(-)$ vector by direct bluntend ligation (resulting plasmid called VP7s-pGEM, 3984 bp, Fig 3) and confirmed by restriction enzymes. EcoR $\mathrm{V}$ has two restriction sites at nucleotides 43 and 556 of VP7 gene, therefore digestion by this enzyme a $513 \mathrm{bp}$ and a $3471 \mathrm{bp}$ fragment were obtained (Figure 4, lane 7). The Nco I enzyme has two restriction sites at recombinant VP7s-pGEM, one at nucleotide 187 
of VP7, and one at nucleotide 37 of pGEM. Therefore a $230 \mathrm{bp}$ (very pale to see) and a 3740 bp fragments resulted from VP7s-pGEM by Nco I digestion (Figure 4, lane 8).

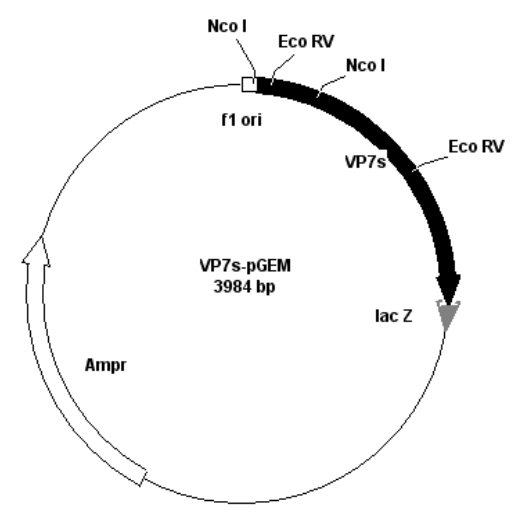

Figure 3 Map of Rcombinant VP7s-pGEM plasmid and it's RE digestion sites.

Figure 4 Cloning of VP7 into the pGEM to construct VP7s-pGEM. 1\% agarose gel electrophoresis at $100 \mathrm{v}, 1$ hour, and gel stained in 1 $\mu \mathrm{g} / \mathrm{ml}$ ethidium bromide. Lanes 1 and 8: DNA molecular weight marker $1 \mathrm{~kb}$ (Fermentas); Lane 2: VP7 RT-PCR product (983 bp); Lane 3 VP7 RTPCR product digested by Dde I (three fragments 118,144 very pale to see and $721 \mathrm{bp}$ ); Lane 4: pGEM plasmid undigested, Lane 5: pGEM plasmid digested by EcoRV (a linear 3001 bp fragment), Lane 6: VP7s-pGEM plasmid undigested; Lane 7: VP7s-pGEM digested by EcoRV (two fragments 3471 \& 513 bp resulted); Lane 8: VP7s-pGEM digested by Ncol (two fragment resulted: a $3740 \mathrm{bp}$ band \& a 230 bp band.

\section{Sequencing}

The clone identified by restriction digestion was subjected to DNA sequencing in the automated ABI $3130 X \mathrm{X}$ genetic analyzer to confirm the sequence fidelity of VP7-pGEM by universal T7 and SP6 primers (BigDye Terminator V3.1 cycle Sequencing Kit). Sequencing result was analyzed by BLAST that had about $100 \%$ homology with SA11 rotavirus genome segment 9 in NCBI GeneBank (2).

\section{Discussion}

The importance of rotavirus as causative agents of gastroenteritis in both young human and animals is well documented (13). Attempts have been made to control and perhaps eliminate mortality due to rotavirus infection by developing and implementing an effective vaccine (7). These developments include making live virus vaccine (14), subunits and other kind of vaccines (5). However, there have been major problems in using these vaccines for prevention of rotavirus gastroenteritis (7). The ideal goal would be to use a vaccine which is effective for protection and has no or minimum side effects (14). We have tried to prepare rotavirus proteins which are involved in virus attachment and neutralization, namely VP4 and VP7.

Our cloning method was simpler than older strategies with the same result, such as in vitro mRNA synthesis using endogenous transcriptase in viral core or using terminal riboadenylate transferase for synthesis of template for full-length cDNA synthesis, $(2,4)$ and this is because of new progress in methodology such as RT-PCR today. Our work confirms nucleotide sequences of gene 9 after long and continuous passage of SA11 rotavirus in our laboratory; however, comparison of our obtained sequence reveals that it has been highly conserved. We omitted $3^{\prime}$ and $5^{\prime}$ noncoding nucleotides from cloned gene, because we want the VP7 gene to be closer to the promoter of appropriate expression vector in future.

This work will be continued to express VP7 in future and will be studied VP7. With large scale expression and purification of VP7 protein, it will be convenient to study VP7 antigenic, immunogenic and biologic functions, which may help for development of an effective vaccine. 


\section{Acknowledgments}

We would like to thank virology department of Iran University of medical sciences for their financial support and national research center of genetic engineering and biotechnology for their technical assistance.

\section{References}

1 Arias, C. F., T. Ballado, and M. Plebanski. 1986. synthesis of the outer-capsid glycoprotein of the simian rotavirus SA11 in Escherichia coli. Gene 47:211-219.

2 Arias, C. F., S. Lopez, J. R. Bell, and J. H. Strauss. 1984. Primary structure of the neutralization antigen of simian rotavirus SA11 as deduced from cDNA sequence. J. Virol 50:657-661.

3 Blutt, S. E., S. E. Crawford, K. L. Warfield, D. E. Lewis, M. K. Estes, and M. E. Conner. 2004. The VP7 outer capsid protein of rotavirus induces polyclonal B-cell activation. J. of Virology 78:6974-6981.

4 Both, G. W., J. S. Mattick, and A. R. Bellamy. 1983. Serotype specific glycoprotein of Simian 11 rotavirus: coding assignment and gene sequence. Proc. Natl. Acad. Sci. USA 80:3091-3095.

5 Conner, M. E., C. D. Zarley, B. Hu, and S. Parsons. 1996. Virus-like particles as a rotavirus subunit vaccine. The journal of infectious diseases 174:S88-92.

6 Estes, M. K. 2001. Rotaviruses and their replication, p. 1747-1785. In D. M. Knipe (ed.), Fields virology, 4th ed, vol. 2. Lippincott William and Wilkins, Philadelphia.

7 Favacho, A. R. M., E. Kurtenbach, S. I. Silva, and V. S. Gouvea. 2006. Cloning, expression and purification of recombinant bovine rotavirus hemagglutenin, VP8*, in Escherichia coli. Protein Expression \& Purification 46:196-203.

8 Fiore, L., S. J. Dunn, B. Ridolfi, F. M. Ruggeri, E. R. Mackow, and H. B. Greenberg. 1995. Antigenicity, immunogenicity and passive protection induced by immunization of mice with baculovirus-expressed VP7 protein from rhesus rotavirus. J Gen Virol $76(\mathrm{Pt}$ 8):1981-8.

9 Johnson, M. A., R. M. Misra, M. Lardelli, M. Messina, C. Ephramus, P. R. Reeves, Z. Bolcevic, J. S. Noel, C. P. Hum, H. Van Mai, M. L. Dyall-Smith, and I. H. Holmes. 1989. Synthesis in Escherichia coli of the major glycoprotein of human rotavirus: analysis of the antigenic regions. Gene 84:73-81.

10 Kapikian, A. Z., Y. Hoshino, and R. M. Chanok. 2001. Rotaviruses, p. 1787-1833. In D. M. Knipe (ed.), Fields virology, 4th ed ed, vol. 2. Lippincott William and Wilkins, Philadelphia.

11 Mandel, M., and A. Higa. 1970. Calcium-dependent bacteroiophage DNA infection. J. Mol. Biol 53:159-162.

12 McGonigal, T. P., M. C. Turon, K. Komar-Hartnett, S. E. Kister, and R. E. Smith. 1992. Expression of the gene coding for the major outer capsid protein of SA-11 rotavirus in a baculovirus system. Virus Res 23:135-50.

13 Parashar, U. D., J. S. Baresee, J. R. Gentch, and R. I. Glass. 1998. Rotavirus. Emerging infectious disease 4:561-570.
14 Peixoto, C., M. F. Q. Sousus, A. C. Silva, M. J. T. Carrondo, and P. M. Alves. 2007. Downstream processing of triple layered rotavirus like particles. Journal of Biotechnology 127:452-461.

15 Promega. 2005. Technical bulletin no 068. 